\title{
Marketing medioambiental a través del análisis de iniciativas empresariales españolas recientes: balance sobre autorregulación y compromiso organizacional sostenible
}

\author{
M. Ángeles Casabó-Ortí \\ Profesora. Universidad Europea de Valencia (España) \\ mariaangeles.casabo@universidadeuropea.es | https://orcid.org/0000-0002-3798-6390
}

Este trabajo ha sido seleccionado para su publicación por: don Ubaldo Cuesta Cambra, doña Alicia Izquierdo Yusta, doña Esmeralda López Alonso, doña Sonia San Martín Gutiérrez y don Francisco Javier Sesé Olivan.

\section{Extracto}

La sostenibilidad, como algo para diseñar por las empresas a largo plazo, dentro y en apoyo del desarrollo económico se puede realizar a través del marketing sostenible, adoptando modelos de producción y consumo sostenibles voluntarios. Con ello se pretende la consecución de los Objetivos de Desarrollo Sostenible (ODS) de la Agenda 2030 de Naciones Unidas. En esta investigación veremos cómo determinadas empresas españolas están empezando a adoptar una actitud activa de responsabilidad hacia la protección del medio ambiente, de conservación y reducción de impacto ambiental hacia los recursos naturales en la producción, así como productos y servicios, que proporcionan una comprensión de las direcciones locales con respecto a la agenda ambiental.

Para ello, las dos grandes perspectivas que se analizan son: la gestión de las empresas (estadísticas europeas EMAS, los galardones y premios europeos y el lugar que ocupan las empresas españolas, Forética y la norma SG21), así como en la seguridad del producto o servicio (ecoetiquetas y cadena de suministro). Con ello, se busca la forma de subir un escalón hacia la excelencia en la gestión, y a través de esta ecoetiqueta también conseguir reconocimiento de terceros.

Palabras clave: sostenibilidad; marketing sostenible; estrategia de negocio; premios; canal de retorno.

Cómo citar: Casabó-Ortí, M. A.A. (2021). Marketing medioambientalatravés delanálisis de iniciativas empresariales españolas recientes: balance sobre autorregulación y compromiso organizacional sostenible. Revista de Marketing y Publicidad. CEF, 4, 61-84. https://doi.org/10.51302/marketing.2021.818 


\title{
The Green marketing of recent Spanish business initiatives: reviewing progress in self-regulation and sustainable organizational commitment
}

\author{
M. a Ángeles Casabó-Ortí
}

\section{Abstract}

Sustainability, as something to be designed by companies in the long term, within and in support of economic development, can be achieved through sustainable marketing by adopting voluntary sustainable production and consumption models. This is intended to achieve the Sustainable Development Goals (SDG) of the United Nations 2030 Agenda. In this research we will see how certain Spanish companies are beginning to adopt an active attitude of responsibility towards the protection of the environment, conservation and reduction of environmental impact towards natural resources in production, as well as products and services, which provide an understanding of local directions regarding the environmental agenda.

For this, the two main perspectives that are analyzed are: company management (European EMAS statistics, European awards and prizes and the place occupied by Spanish companies, Forética and the SG21 standard), as well as product safety or service (eco-labels and supply chain). With this, a way is sought to climb a step towards excellence in management, and through this eco-label also obtain recognition from third parties.

Keywords: sustainibility; Green marketing; business strategy; enviromental awards; green reverse logistics.

Citation: Casabó-Ortí, M. ${ }^{a}$ A. (2021). Marketing medioambiental a través del análisis de iniciativas empresariales españolas recientes: balance sobre autorregulación y compromiso organizacional sostenible. Revista de Marketing y Publicidad. CEF, 4, 61-84. https://doi.org/10.51302/marketing.2021.818 


\section{Sumario}

1. Introducción

2. Objetivos y metodología del trabajo y el marketing medioambiental

3. Un examen de estrategia de marketing sostenible medioambiental: el caso de las empresas españolas

\subsection{Gestión}

3.2. Seguridad del producto o servicio

\subsubsection{Etiqueta ecológica}

\subsubsection{Cadena de suministro}

4. Conclusiones

Referencias bibliográficas 


\section{Introducción}

Krznaric (2020) en su libro El buen antepasado: cómo pensar a largo plazo en un mundo a corto plazo ${ }^{1}$ trata de la necesidad de la toma de decisiones sabias y a largo plazo, especialmente en esta época marcada por la crisis de la covid, para podernos convertir en los «buenos antepasados» (good ancestors) que se merecen las generaciones futuras. Para ello plantea el concepto «pensamiento catedral» (Rodríguez, 29 de diciembre de 2020), como visión de hacer algo a muy largo plazo. Especialmente traza este concepto en relación con la sostenibilidad, como algo para diseñar por las empresas para crear planes de sostenibilidad a 100 años. Compartimos totalmente su filosofía, propia de los Objetivos de Desarrollo Sostenible de las Naciones Unidas (ODS), y esto se puede realizar a través de herramientas de marketing. Es necesario que se logre un buen equilibrio entre la competitividad y el desarrollo sostenible, especialmente en los negocios, pues estos se cuantifican en meses y trimestres, frente a la sostenibilidad, que a menudo requiere costes significativos a corto plazo para asegurar un beneficio a largo plazo. Nadie niega seriamente la necesidad de prácticas comerciales sostenibles, incluso por aquellos que se preocupan solo por sus negocios y no por el destino del planeta, pues reconocen que la viabilidad de los negocios en sí depende de los recursos de ecosistemas saludables (agua dulce, aire limpio, biodiversidad, tierra productiva, etc.), así como de la estabilidad de sociedades justas. Aunque la sostenibilidad como concepto se aborda desde diferentes perspectivas y definido por varios autores (Brío y Junkera, 2011; Kumar, 2013), la definición de sostenibilidad ampliamente utilizada es la de las Naciones Unidas en el informe Brundtland: «Satisfacer las necesidades de las generaciones actuales sin comprometer la capacidad de las generaciones futuras para satisfacer sus propias necesidades» (WCED, 1987, p. 24). Ahora estamos en medio de otra revisión del concepto, en la que las consideraciones de impacto impregnan toda la toma de decisiones de las empresas. Fruto de este cambio está surgiendo una imagen completamente diferente de cómo prosperar en los negocios, que se puede ver resumida en las palabras del CEO de Dow Chemical ${ }^{2}$, Andrew Liveris, convencido de hacer operativa la sostenibilidad: «Las empresas que valoran e integran la biodiversidad y los servicios de los ecosistemas en sus planes estratégicos están mejor posicionadas para

1 Del original The good ancestor: how to think long term in a short-term world.

2 En 2011, Dow Chemical (corporate.dow.com; tiene presencia en 175 países, 43.000 empleados y ventas anuales por 49.000 millones de dólares.) prometió 10 millones de dólares durante cinco años para un equipo de científicos de The Nature Conservancy para ayudar a Dow a desarrollar métodos de valoración de servicios ambientales. En <https://www.businesswire.com/news/home/20110124006239/en/ Dow-and-The-Nature-Conservancy-Announce-Collaboration-to-Value-Nature>. 
el futuro». Al mismo tiempo, se ha realizado una gran cantidad de investigaciones para explorar cómo se puede lograr la sostenibilidad en la práctica y sus principales efectos en las empresas, los negocios y la sociedad en su conjunto (Hunt, 2011). En particular, ha habido mucho interés en examinar cómo debe evolucionar la función del marketing para adoptar un desarrollo sostenible. Van Dam y Apeldoorn (1996) definieron el «marketing sostenible» como marketing dentro y en apoyo del desarrollo económico sostenible.

Nos hemos preguntado cuál es la situación en España respecto al marketing sostenible. En la presente investigación se van a poner en valor las iniciativas, documentando más de 200 actividades valiosas que las empresas sostenibles llevan a cabo en el área del marketing sostenible, en concreto en relación con la gestión y seguridad del producto o servicio. Los casos estudiados incluyen un intento de radiografía de la realidad del país.

Hoy, los países que realmente se están ocupando de la planificación ambiental y supervisión son los países de la Unión Europea que llevan a cabo una política medioambiental común de conformidad con los acuerdos ambientales internacionales (Yilmazer y Onay, 2019, p. 238). Así, la Comisión Europea, en Documento de reflexión para una Europa sostenible de aquí a $2030^{3}$, de enero de 2019 , en su prólogo ${ }^{4}$ afirma que:

El desarrollo sostenible es una cuestión compleja, pero un concepto sencillo: se trata de garantizar que nuestro crecimiento económico nos permita mantener un modelo que produzca resultados equitativos para toda la humanidad, y garantizar que no se consuman más recursos de los que la tierra puede ofrecer. Esto significa que tenemos que modernizar nuestra economía, adoptando modelos de producción y consumo sostenibles, para corregir los desequilibrios existentes en nuestro sistema alimentario, y colocar nuestra movilidad y la manera en que producimos y utilizamos la energía y diseñamos edificios en una senda sostenible. Para ello, también debemos orientar toda nuestra ciencia, financiación, fiscalidad y gobernanza hacia la consecución de los ODS.

Destaca, por tanto, la necesidad de adoptar modelos de producción y consumo sostenibles, así como la consecución de los ODS de la Agenda 2030 de Naciones Unidas como un planteamiento teleológico. Entre estos objetivos está el 12, que hace referencia a «Producción y consumo responsable», y más específicamente el 12.6: «Alentar a las empresas, en especial las grandes empresas y las empresas transnacionales, a que adopten prácticas sostenibles e incorporen información sobre la sostenibilidad en su ciclo de presentación de informes».

Con el Libro Verde de la Unión Europea (UE 18 de julio de 2001) se materializó el compromiso de la UE a favor de la RSE.

3 <https://ec.europa.eu/commission/sites/beta-political/files/rp_sustainable_europe_es_v2_web.pdf>.

4 Prólogo del vicepresidente primero Timmermans y del vicepresidente Katainen. 
Mediante un comportamiento socialmente responsable, las empresas pueden desempeñar un papel esencial para favorecer que la UE avance hacia su objetivo de mayor crecimiento económico, competitividad, justicia social y desarrollo sostenido. En 2002, la Comisión Europea define la Responsabilidad Social como «la integración voluntaria, por parte de las empresas, de objetivos sociales y medioambientales en sus operaciones comerciales y en sus relaciones con el resto de actores implicados» 5 .

Años más tarde en el informe de la subcomisión parlamentaria para promover la RSE, esta explicaba que:

La responsabilidad social de la empresa es, además del cumplimiento estricto de las obligaciones legales vigentes, la integración voluntaria por parte de la empresa, en su gobierno y gestión, en su estrategia, políticas y procedimientos, de las preocupaciones sociales, laborales, ambientales y de respeto a los derechos humanos que surgen de la relación y el diálogo transparentes con sus grupos de interés, responsabilizándose así de las consecuencias y de los impactos que derivan de sus acciones. (Incluida en la Estrategia Española de la Responsabilidad Social de la Empresa, EERSE) ${ }^{6}$.

A través de la integración de la responsabilidad social corporativa, las empresas enfocan parte de las actividades de la cadena de valor hacia el beneficio de la sociedad y entorno, creando valor compartido, lo que incentiva a la innovación y crecimiento económico (Navarro y Revilla, 2020). La creciente degradación del medio ambiente ha traído consigo que las empresas e industrias comiencen a utilizar nuevos instrumentos de protección ambiental, aunque sean de carácter voluntario, en el contexto de una nueva ética empresarial. Algunas empresas pioneras han demostrado que aplicar prácticas de marketing más sostenibles es una estrategia de marketing eficaz, como veremos más adelante.

\section{Objetivos y metodología del trabajo y el marketing medio- ambiental}

De las tres dimensiones de la sostenibilidad (medioambiental, social y económica) que están relacionadas y son interdependientes, vamos a centrarnos en esta investigación en la medioambiental, entendida como la preservación continua de ecosistemas esenciales y sus funciones (Hawken, 2007, p. 13). El objetivo de este análisis es explorar la situación del marketing medioambiental en España a través del análisis de la situación de autorregula-

5 Comunicación de la Comisión de la Unión Europea de 2 de julio de 2002, Bruselas <http://www.europarl. europa.eu/meetdocs/committees/empl/20021111/com(2002)347_ES.pdf>.

6 En <http://www.mites.gob.es/ficheros/rse/documentos/eerse/EERSE-Castellano-web.pdf>. 
ción y compromiso organizacional sostenible de las empresas españolas. Veremos cómo determinadas empresas están empezando a adoptar una actitud activa de la responsabilidad hacia la protección del medio ambiente, de conservación y reducción de impacto ambiental hacia los recursos naturales en la producción, así como productos y servicios, que proporcionan una comprensión de las direcciones locales con respecto a la agenda ambiental. Para ello, se han estudiado estadísticas de la Unión Europea, estadísticas de agencias acreditadores e informes del mercado comercial y privado. Estos diferentes conjuntos de datos se verifican de forma cruzada para garantizar la coherencia y para garantizar que se compare la misma categoría de responsabilidad. Con la visión fenomenológica/descriptiva de lo que se está haciendo en España, se busca una doble finalidad: por un lado, se pone en valor lo realizado por empresas españolas, comparándolo con la situación en Europa, y por otro, se busca que otras empresas, al conocer estas iniciativas, encuentren una inspiración para que ellas emprendan acciones voluntarias para reducir el impacto ambiental de sus negocios, y no simplemente en el mero cumplimiento de determinados límites a través de la legislación medioambiental. Con ese carácter, un tanto pedagógico, se definen conceptos para clarificar y precisar cuestiones terminológicas.

El marketing sostenible, en la definición de Fuller (1999) es:

El proceso de planificación, implementación y control del desarrollo, precios, promoción y distribución de productos de modo que satisfaga los tres criterios siguientes: satisfacción de las necesidades del cliente, consecución de los objetivos de la empresa y compatibilización del proceso con el ecosistema.

Las instituciones de marketing deben poder para alcanzar sus propias metas económicas y financieras, y el marketing sostenible no es diferente a este respecto. Sin embargo, para ser sostenible, el marketing también debe atender activamente su impacto en el medio ambiente natural y en el bienestar humano. El marketing, junto con prácticamente todas las demás cuestiones comerciales, está experimentando un cambio importante hacia la sostenibilidad medioambiental y social (Hart y Stuart, 1995, p. 986). Es necesario entender a Elkington (1994), para el que el desarrollo sostenible en la empresa es aquel que contribuye a la gestión responsable mediante la entrega al mismo tiempo de beneficios económicos, sociales y medioambientales, la llamada triple bottom line (TBL) ${ }^{7}$. Con ese espíritu, Martin

7 Altinbasak-Farina y Burnaz (2019) hacen un breve resumen de cómo los distintos conceptos han sido entendidos por la doctrina: «Del mismo modo, Sheth et al. (2011) afirmó que la sostenibilidad se traduce en un "triple resultado" de responsabilidad, con la implicación de que la evaluación de los resultados comerciales debe basarse no solo en el desempeño económico, pero también debe tener en cuenta el impacto ambiental y social. El triple blottom se ha extendido a diferentes marcos, como las 3 Es (economic vitality, environmental quality, and equal opportunity/vitalidad económica, calidad ambiental e igualdad de oportunidades), las $3 \mathrm{P}$ (people, planet, and profit/personas, planeta y ganancias), y la visión más tradicional de triple resultado como medio ambiente integridad, prosperidad económica y justicia social/ environmental integrity, economic prosperity, and social justice (Hult 2011: XIV)». 
y Schouten (2014) dan una definición de marketing sostenible: «El marketing sostenible es el proceso de crear, comunicar y entregar valor para los clientes de tal manera que se preserven tanto el capital natural como el humano o mejorado en todo».

Por tanto, el verdadero contenido de la responsabilidad social está en la integración de las finalidades propias de la empresa y de la sociedad, en la consideración de los valores sociales y en la integración de la actividad empresarial. De ahí que la responsabilidad social debe entenderse como una responsabilidad integral, amplia e inseparable de la propia responsabilidad económica. (Valle, 2010, p. 28).

Con fines de planificación estratégica, para llevar a las empresas hacia la sostenibilidad, los instrumentos voluntarios que se van a estudiar se dividen en dos categorías principales: aquellos orientados al proceso y los orientados al producto. Los relativos al proceso se refieren a los instrumentos que guían a las empresas a internalizar y orientar sus procesos o conjunto de operaciones hacia un impacto reducido sobre el medio natural y el medio ambiente. Mientras que los orientados al producto tratan principalmente del etiquetado medioambiental de productos (etiquetas ecológicas), cuyo objetivo es promover productos con menores efectos ambientales adversos (Galarraga, 2002), y al ciclo de vida del producto ambiental, que evalúa el impacto ambiental de un producto durante toda su vida útil (Guinée y Lindeijer, 2002).

\section{Un examen de estrategia de marketing sostenible medio- ambiental: el caso de las empresas españolas}

Como ya se ha afirmado anteriormente, el propósito de esta investigación es comprender la planificación estratégica como instrumento de la sostenibilidad ambiental en empresas españolas. Con carácter previo, en España observamos el perfil de las sociedades mercantiles existentes, a finales de 2020, según su actividad económica principal (gráfico 1). El más numeroso es la empresa de comercio al por mayor y al por menor. El número de empresas que hay en hostelería es similar al número de la empresa en la industria. Por tanto, como punto de partida para entender mejor la situación, las dos grandes perspectivas que se van a analizar son la gestión de las relaciones comerciales, así como la seguridad del producto o servicio. Consideramos que son las que mejor muestran compromiso organizacional sostenible.

\subsection{Gestión}

Las empresas más concienciadas con la sostenibilidad prestarán más atención a los problemas ambientales mientras desarrollan sus estrategias de gestión y marketing. Un sistema de gestión consiste en un conjunto de controles, procesos y procedimientos do- 
cumentados $^{8}$ revisados por la dirección. Este enfoque se caracteriza por precisar de la reorientación medioambiental de todos los sistemas productivos, directivos y comerciales, y supone la adopción de una visión holística de la organización que implica que todos los departamentos y miembros organizacionales comprendan, compartan y asuman una serie de valores comunes (Rivera, 2007). Este sistema de gestión, concienciado con el medio ambiente, puede ser bien a nivel interno o bien ser más ambicioso (y complejo), desarrollarse conforme a una norma integrada en un sistema de gestión certificado. Al implementar una gestión sostenible en la comercialización, la empresa tiene como desafíos la incorporación de estándares de sostenibilidad en las políticas de ventas, la realización de actividades que contribuyen a promover y mejorar la responsabilidad y sostenibilidad de los clientes y la verificación del grado de cumplimiento de los estándares establecidos, y todos de forma alineada. En esta estandarización de la responsabilidad social (RS) existen dos tipos de normas: los estándares sobre la gestión de gestión estratégica de la RS y los de reporte de sostenibilidad. Los instrumentos orientados al proceso guían a las empresas a internalizar y orientar sus procesos hacia un impacto menor sobre el medio natural medio ambiente (Harvanová, 2018), y no entraremos, por la extensión de este estudio, en los reportes de sostenibilidad.

Gráfico 1. Porcentaje de sociedades mercantiles según su actividad económica principal

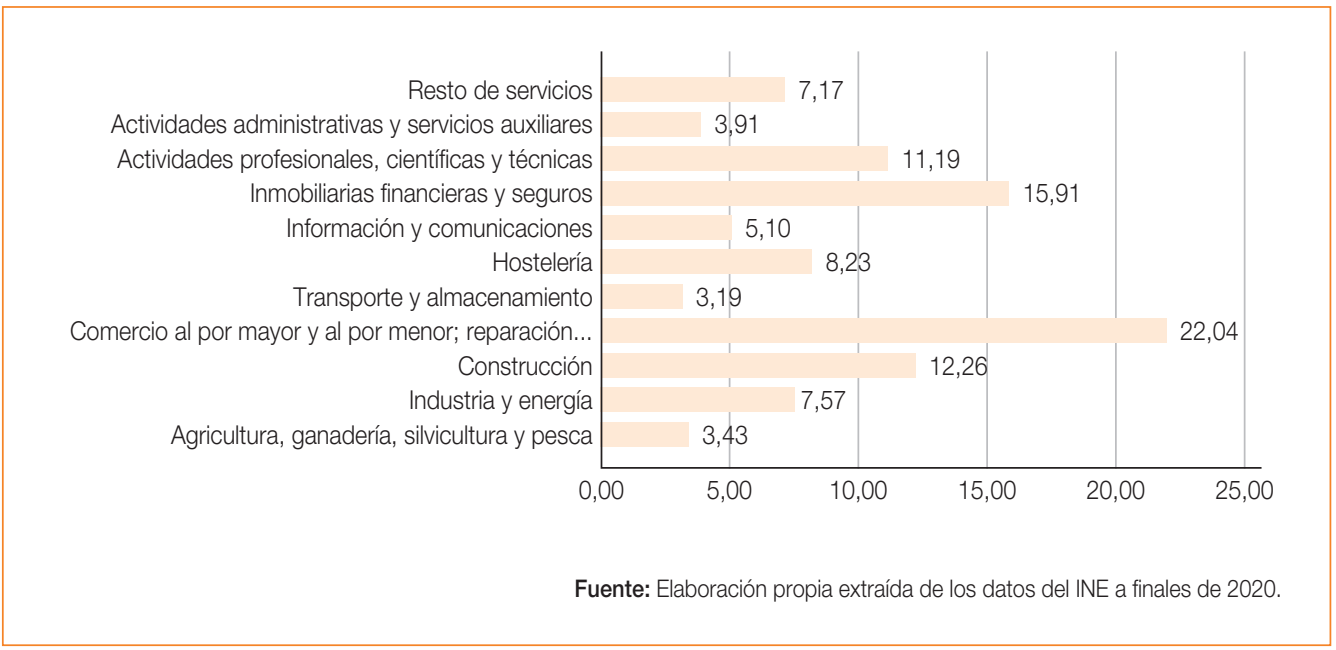

Para esta investigación se presentarán, en primer lugar, las estadísticas europeas sobre European Union's EcoManagement and Audit Scheme o EMAS, que es una herramienta

8 Es decir, un procedimiento documentado consiste en una descripción escrita de la manera correcta de proceder o de un proceso para gestionar y controlar las actividades de la organización. 
de gestión voluntaria que permite evaluar, mejorar y dar a conocer su comportamiento ambiental de una empresa. Posteriormente, se abordarán los galardones y premios europeos y el lugar de las empresas españolas, que es un indicador de éxito. En último lugar, se analizará la propuesta de Forética y la norma SG21, que ha tenido una gran demanda entre los empresarios españoles. Somos conscientes de que existen otras normas sociales relevantes $^{9}$, sin embargo, por la extensión de esta investigación, es imposible examinarlos, por lo que se deja para investigaciones futuras.

Pasando a la primera cuestión, la European Union's EcoManagement and Audit Scheme (EMAS) o Sistema de Ecogestión y Auditoría (EMAS) es un reglamento voluntario que define el Sistema de Gestión Ambiental (SGA), y se centra principalmente en las normas medioambientales. La Unión Europea quiere identificar las mejores estrategias y medidas adoptadas por las organizaciones registradas en EMAS y aumentar su visibilidad para promover su reproducción en toda la Unión Europea, y para ello existe un registro que

constituye un valioso instrumento de la política ambiental al contribuir tanto a la consecución de los objetivos del Acuerdo de París como a la de los Objetivos de Desarrollo Sostenible, ya que garantiza las innovadores medidas de producción que desarrollan las empresas inscritas en él ${ }^{10}$.

La tabla 1 nos muestra todas las organizaciones que han implantado un sistema EMAS y que aparecen en la base de datos europea denominada EU EMAS Register. En la misma vemos que en el número de empresas ${ }^{11}$, el primer país es Alemania, con 1.131 empresas, el segundo es Italia, con 1.010, y el tercero es España, con 962.

Respecto a nuevos registros, en el gráfico 2 se observa como Italia (43\%) y España (28\%) son los países que de septiembre de 2019 a abril 2020 han tenido mayores certificaciones, lo que supone una tendencia al alza por parte de las empresas españolas.

Otro indicador de calidad y de motivación, fruto de este interés de la Unión Europea, son los diversos premios a la calidad, y que consideramos como parte de la estrategia para la competitividad por parte de las empresas españolas. Los premios procuran el reconocimiento a las empresas e instituciones que son ejemplares en gestión de la calidad y excelencia en

9 Como ISO26000 Directrices sobre Responsabilidad Social, SA8000 Sistema de Gestión Social, I1 Net SR10, etc.

10 En <https://www.miteco.gob.es/es/prensa/ultimas-noticias/convocados-los-premios-emas-2019-dedicados-este-a\%C3\%B1o-a-la-transici\%C3\%B3n-sostenible/tcm:30-496529>.

11 No nos interesa analizar el número de emplazamientos, pues su número es menos representativo. Por ejemplo, en Italia, una sola empresa (Unicredit, S.p.A., la compañía bancaria con gran número de clientes) tiene un número de emplazamientos de 4.342, sobre un total de 4.933 emplazamientos en Italia. 
tema de sostenibilidad. Los galardones más prestigiosos en materia de gestión ambiental entregados por la Unión Europea son los premios «EMAS como motor del cambio - EMAS Driver of Change ${ }^{12}$, y pueden aspirar tanto las pequeñas, medianas y grandes empresas privadas como las organizaciones públicas adheridas al registro EMAS. Es muy significativo cómo en la edición de 2019 la temática con el lema «EMAS como motor del cambio hacia una transición sostenible», se ha reconocido la labor de tres empresas españolas; tres premios de los cinco otorgados, en materia medioambiental. En entidades públicas medianas y grandes a las autoridades portuarias de Barcelona y Cartagena ${ }^{13}$, cada una en su propia categoría. La Autoridad Portuaria de Barcelona destaca por el desarrollo de su Plan de Mejora de la Calidad del Aire, que apuesta por la promoción de combustibles más limpios dentro de la cadena logística portuaria, mientras que la Autoridad Portuaria de Cartagena pretende convertirse en referente en cuanto a gestión eficaz y sostenible de sus servicios.

Tabla 1. Estadística oficial de EMAS (septiembre 2020)

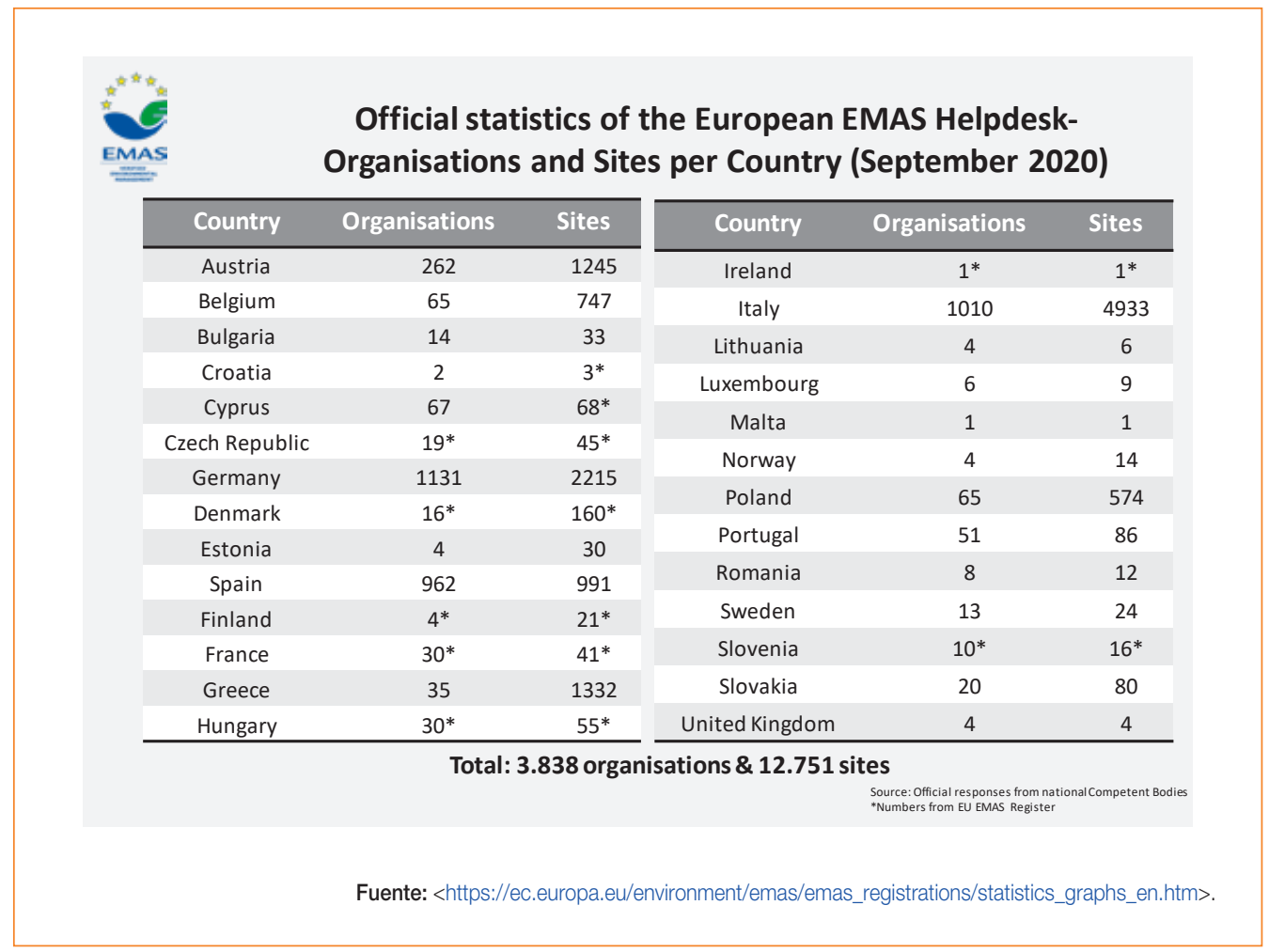

\footnotetext{
12 Desde 2005, estos galardones de la Comisión Europea se dedican cada edición a una temática específica.

13 En <https://www.tiempo.com/ram/premios-emas-2019.html>.
} 
Gráfico 2. EMAS. Nuevos registros (septiembre/octubre 2019-abril 2020)

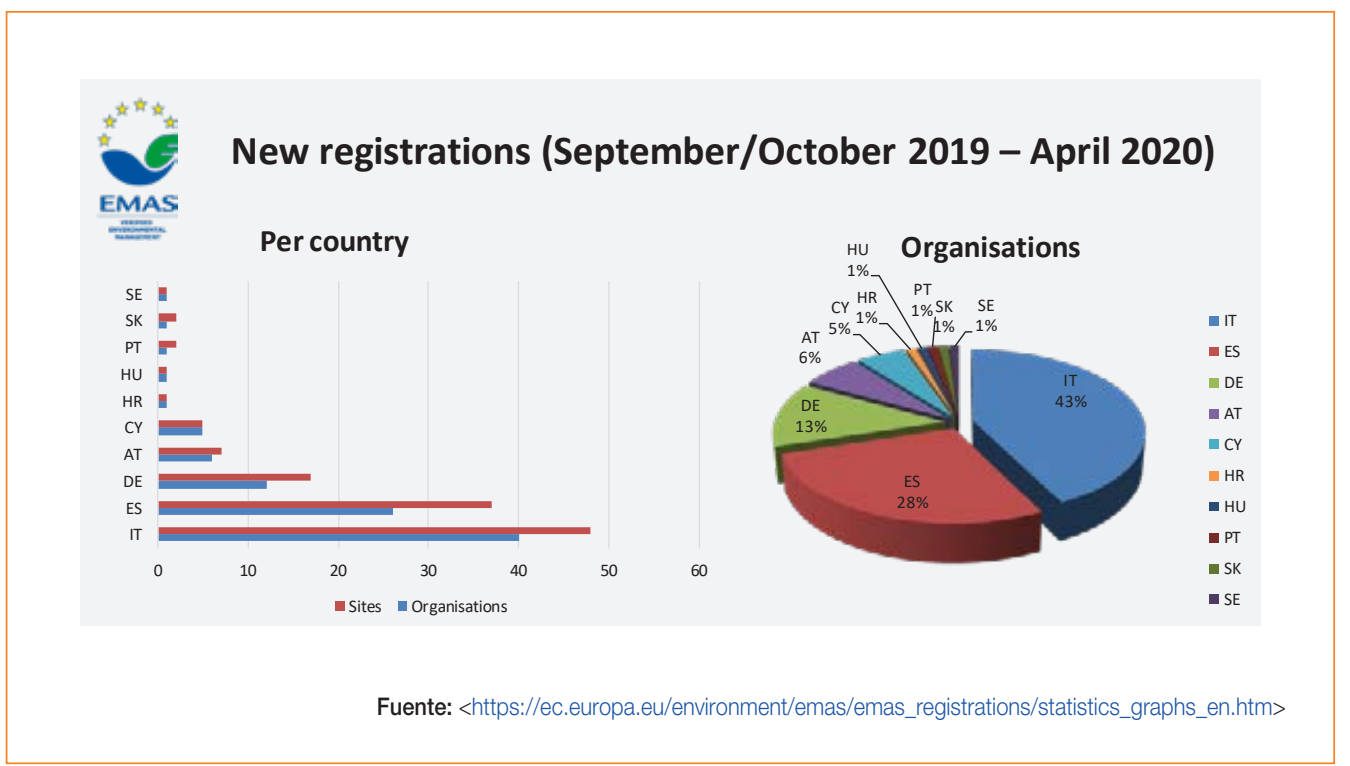

En grandes empresas ganaron los Laboratorios Servier ${ }^{14}$. Es una empresa encargada de diseñar, desarrollar y producir productos para la industria farmacéutica desde una perspectiva responsable en el uso los recursos y la promoción del desarrollo global y sostenible. Es muy significativo cómo los premios se entregaron en Bilbao (País Vasco), pues es una de las regiones de Europa con mayor número de organizaciones EMAS por habitante; actualmente hay 83 entidades vascas registradas.

Otros premios europeos son los Premios Europeos de Medio Ambiente a la Empresa (EBAE), que se convocan desde 1987 por parte de la Comisión Europea para reconocer a aquellas empresas que combinan con éxito la viabilidad económica de sus negocios con la protección del medio ambiente (innovación, competitividad y un rendimiento medioambiental sobresaliente). Entre ellas, y de todas las candidaturas finalistas, se eligió la española Tejidos Royo como una de las seis empresas más sostenibles a nivel europeo, en la categoría de proceso $^{15}$. La empresa ha sido precursora en la tecnología de tintura con espuma, además de ser la primera empresa textil en Europa en utilizar materias primas de bajo impacto

14 Además de la verificación de AENOR en el Reglamento EMAS, Laboratorios Servier tiene los certificados ISO 9001 de gestión de la calidad, ISO 14001 de gestión ambiental, ISO 45001 de gestión de la seguridad y salud en el trabajo, y UNE 166002 de gestión de I+D+i.

15 En <http://www.tejidosroyo.com/post/tejidos_royo_obtiene_el_premio_europeo_del_medio_ambiente_a_ la_empresa_gracias_a_su_tecnologia_dry_indigo>. 
(reciclado pre-post consumer, Tencel® y fibras de origen orgánico) para la creación de sus tejidos, y cuenta con la exclusiva mundial de la tecnología Dry Indigo®.

El último indicador de gestión sostenible que vamos a analizar lo encontramos a través de la norma SGE 21, que

ayuda en la implementación y evaluación de un Sistema de Gestión Ética y Socialmente Responsable como la primera norma europea (desde 1999) que ha desarrollado los requisitos para implantar, auditar y certificar un sistema de gestión ética y socialmente responsable, el cual supone un compromiso de liderazgo responsable por parte de dirección ${ }^{16}$.

Resulta ser una herramienta potencial para la integración de los aspectos sostenibles en la gestión de empresas u organizaciones y es el primer sistema de gestión de la responsabilidad social europeo que permite, de manera voluntaria, auditar procesos y alcanzar una certificación en gestión ética y responsabilidad social por parte de Forética que es el Foro para la Evaluación de la Gestión Ética y que ofrece a sus socios soluciones innovadoras en esta materia.

Gráfico 3. Norma SGE 21 Forética. Año de certificación de las empresas

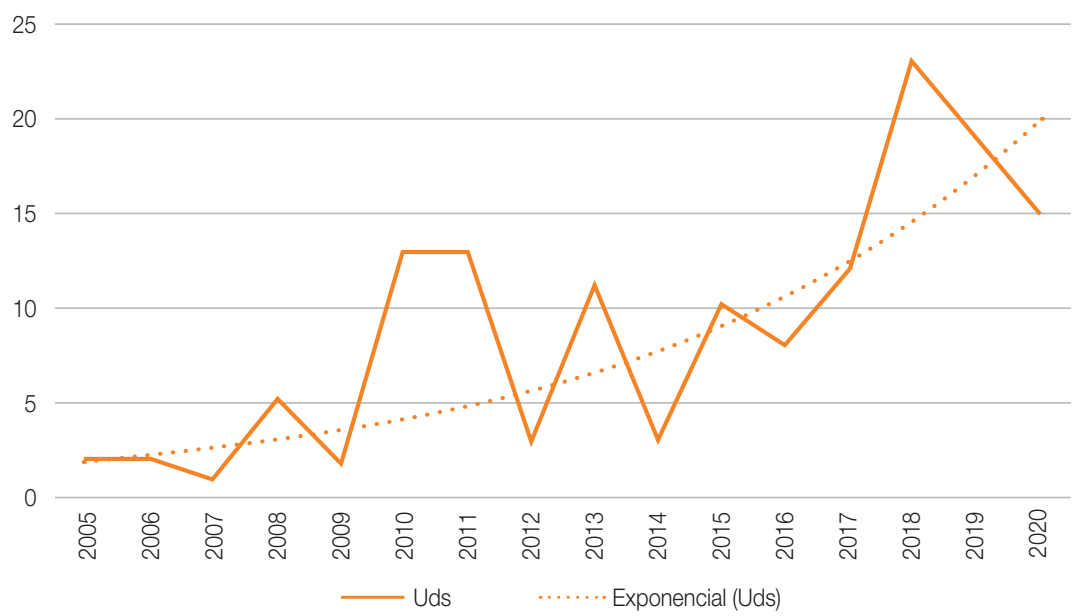

Fuente: Elaboración propia.

16 En <http://foretica.org/sge21/>. 
En el gráfico 3, durante el periodo de 2004 a 2020, en el número de empresas que han sido certificadas por la norma SGE 21 se observa una tendencia al alza en el interés de certificarse por parte de las empresas, sobre todo en los últimos cinco años. A nivel español Forética está atrayendo atención para las empresas, pues estas pueden recibir un asesoramiento personalizado sobre cómo certificarse, a diferencia de EMES.

De las empresas certificadas, la mayoría son españolas (142), pero también hay tres colombianas, una peruana y tres portuguesas. En cuanto a la actividad o servicio de las empresas certificadas con la SGE21, se observa un claro predominio (gráfico 4) de las empresas de servicios (45), que son las más interesadas en esta certificación, seguidas muy por debajo por las de trabajo temporal (10), transporte (9), limpieza (8), construcción (7) y, con 6 empresas cada una, los servicios funerarios y servicios sociales.

Gráfico 4. Norma SGE 21 Forética. Actividades/servicios de las empresas certificadas

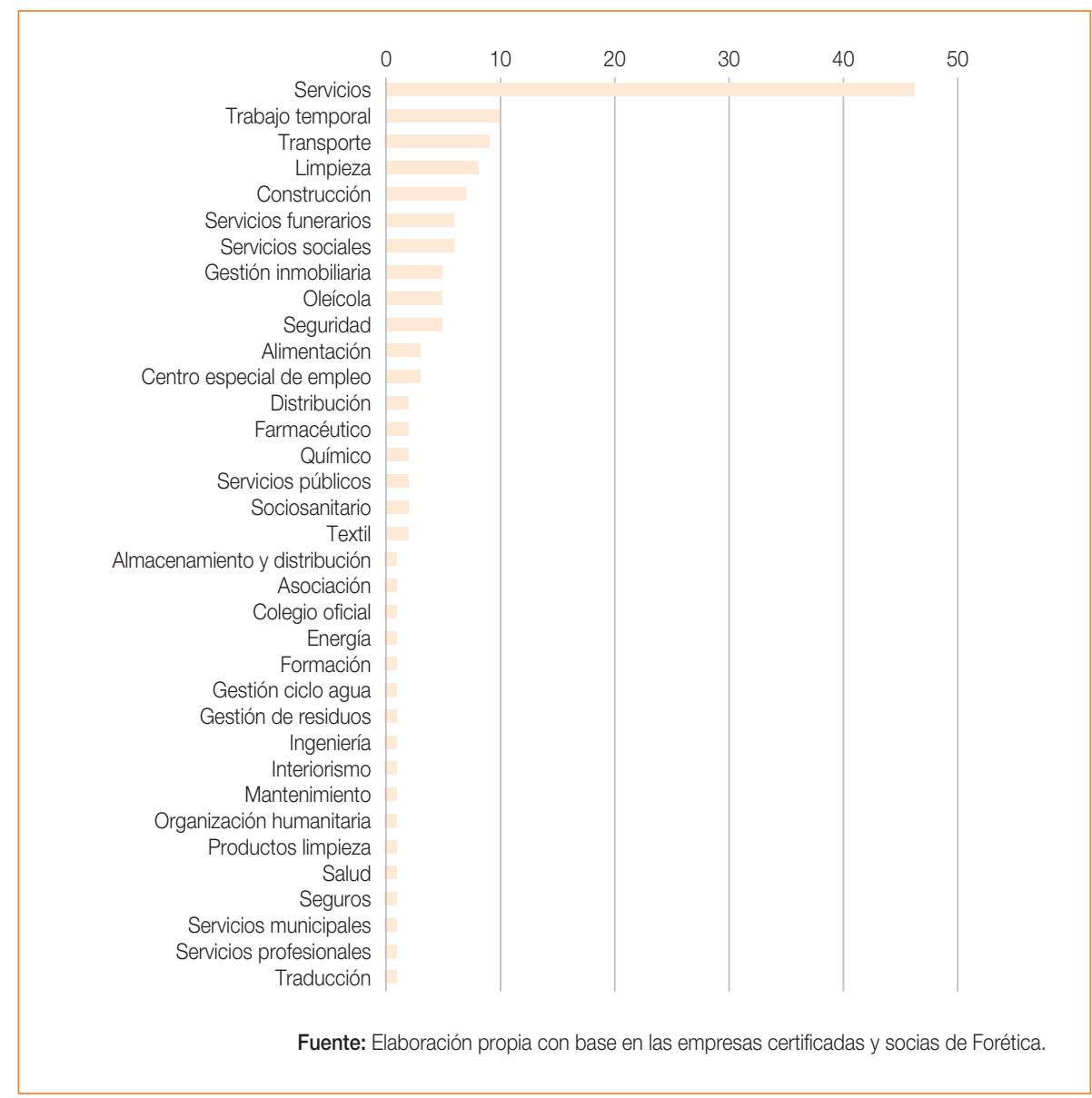




\subsection{Seguridad del producto o servicio}

Un eje fundamental del marketing sostenible recae en la seguridad del producto o servicio. Es decir, toda empresa sostenible se esfuerza por entregar y desarrollar productos y servicios seguros y confiables a sus clientes con el fin de garantizar las especificaciones técnicas del producto o servicio, incluida la salud, seguridad y medio ambiente, así como las condiciones de uso y conservación, y que esta información se transmita debidamente al cliente. Por tanto, los principios de calidad, tanto en la prestación del producto como en la prestación del servicio, deben formar parte de la cultura organizativa para conseguir la máxima satisfacción del cliente y para que la empresa pueda seguir siendo competitiva en el mercado.

El reto para las empresas es conseguir la certificación en la ecoetiqueta como forma de subir un escalón hacia la excelencia en la gestión, y a través de esta ecoetiqueta también conseguir reconocimiento de terceros.

\subsubsection{Etiqueta ecológica}

En la actualidad existe un gran número de etiquetas, logos o sellos, algunos de cuales son simplemente una labor de marketing. La necesidad de transparencia ha dado lugar a la aparición de sistemas normalizados, entre los cuales destaca la etiqueta ecológica de la Unión Europea. (Guillén, 2020). Las ecoetiquetas son sistemas voluntarios que tienen como objetivo promover bienes de consumo que tengan un bajo impacto ambiental en comparación con otros productos de la misma categoría. Desde la Unión Europea, la etiqueta ecológica es un sistema fiable, transparente y no discriminatorio válido en toda la Unión Europea y en los países de la AELC (Noruega, Islandia, Suiza y Liechtenstein) ${ }^{17}$, y es el programa de ecoetiquetado más importante a nivel europeo. El símbolo es una flor de color verde y que comúnmente se conoce como la margarita europea. El grupo objetivo son los productos y servicios de consumo final, excluyéndose alimentos y medicamentos.

En septiembre de 2020 (figura 1), 75.796 productos o servicios de los países miembros de la Unión Europea recibieron la Ecolabel. Entre las categorías, Hazlo tú mismo (Do-it-yourself) fue con creces la más que más etiquetas tuvo (28.739), seguida por Papel (Paper) con 18.666.

De forma más específica, por países, vemos que España ha conseguido 15.768 productos en el sistema de acreditación voluntaria de productos y servicios, y ocupa el primer lugar con casi el $21 \%$ de Ecolabel. Este interés de la empresas españolas es digno de mención, y debería ser puesto en valor de forma más intensa. A nivel de productos que han obtenido

17 En <https://www.miteco.gob.es/es/calidad-y-evaluacion-ambiental/temas/etiqueta-ecologica-de-launion-europea/>. 
la ecoetiqueta en España, en la tabla 2 se observa que en su mayoría son los revestimientos duros ${ }^{18}$, papel tisú y productos de limpieza de superficies duras ${ }^{19}$.

Figura 1. EU Ecolabel key figures

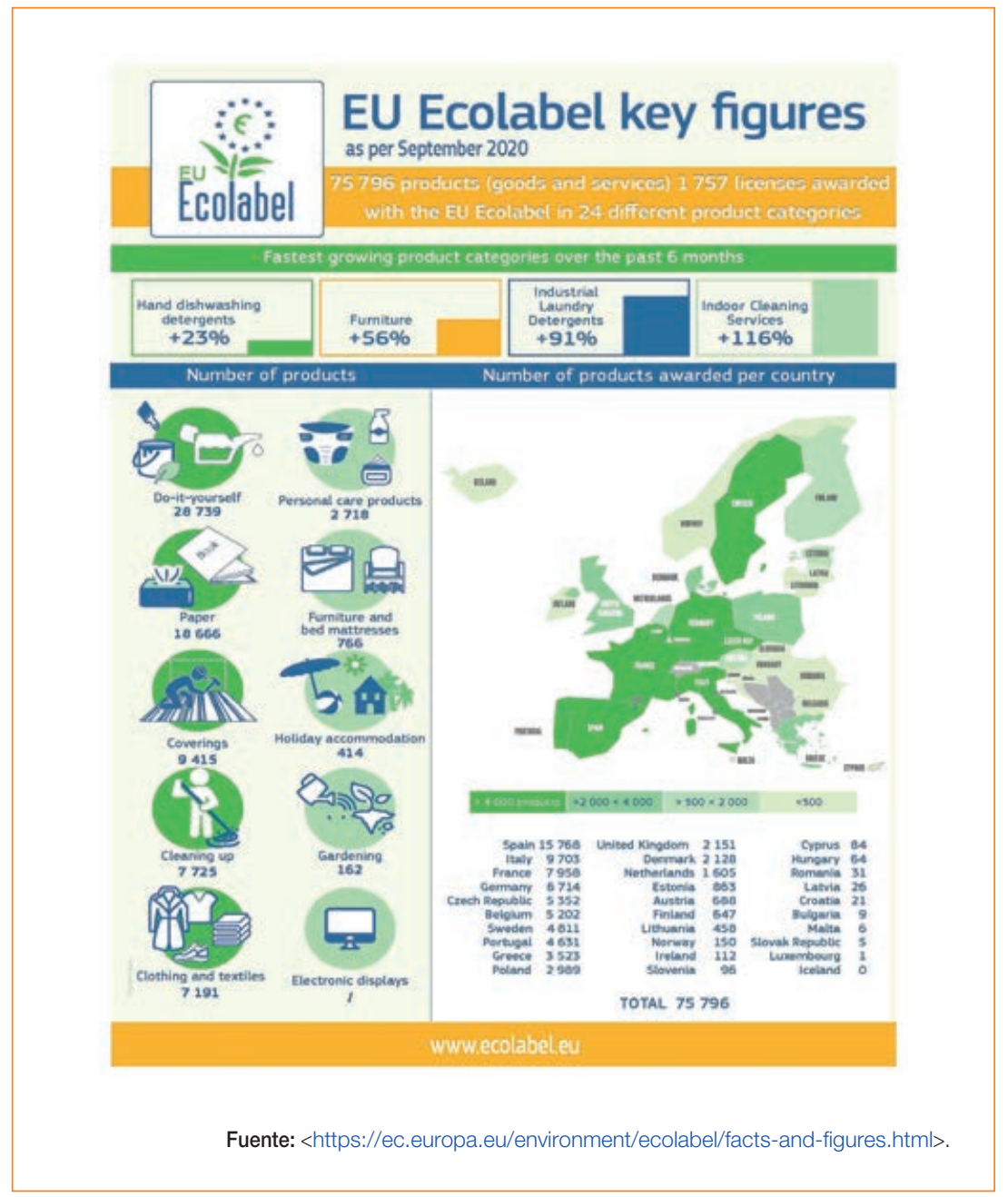

18 Incluye piedras naturales, piedras aglomeradas, adoquines de hormigón, mosaicos, tejas cerámicas y tejas de arcilla, aptas para uso interior y exterior sin ninguna función estructural. Sus características han sido estudiadas por Monfort (2011).

19 Entendidos como cualquier limpiador multiusos, limpiador de cocina, limpiador de ventanas o limpiador sanitario. 
La producción de papel en España creció el 4,5\% en 2019, ligada al papel de envases y embalajes y los papeles sanitarios ${ }^{20}$. Encontramos información sobre el sector en Euler Hermes ${ }^{21}$ y su informe Addressing needs of tissue and wrapping papers following the surge in health and e-commerce activities due to the pandemic, que determinó, como puntos a favor, la creciente necesidad de envases de cartón en línea con las crecientes actividades del comercio electrónico, nuevas oportunidades de mercado debido al crecimiento de la clase media en los mercados emergentes o una fuerte demanda de productos de higiene. Para la concesión de la misma, se tiene en cuenta: toxicidad para los organismos acuáticos, biodegradabilidad, uso sostenible de recursos de aceite de palma, aceite de palmiste y sus derivados, sustancias excluidas y restringidas, características de empaque e idoneidad para el uso e información del usuario ${ }^{22}$. La suma de distintos tipos de detergentes también es muy mayoritario.

Tabla 2. Tipos de productos españoles con ecoetiqueta

Total general

Revestimientos duros / Hard coverings

Papel tisú y productos tisú / Tissue paper and tissue products

Productos de limpieza de superficies duras / Hard surface cleaning products

260

Pinturas y barnices para interior y exterior/ Indoor and outdoor paints and varnishes

Detergentes para ropa / Laundry detergents

Detergentes para lavavajillas a mano / Hand dishwashing detergents

Detergentes para lavavajillas automáticos industriales e institucionales / Industrial and institutional automatic dishwasher detergents

Productos cosméticos que se aclaran / Rinse-off cosmetic products

Detergentes para lavavajillas / Dishwasher detergents

20 En <http://www.aspapel.es/content/aspapel-presenta-el-informe-anual-del-sector-papelero>.

$21<\mathrm{https}$ ///www.eulerhermes.com/en_global/economic-research/sector-reports/paper.html>.

22 Decisión (UE) 2017/1219 de la Comisión. En <https://eur-lex.europa.eu/legal-content/ES/TXT/PDF/?uri $=$ CELEX:32017D1219\&from $=$ HU>. 
Detergentes para ropa industriales e institucionales / Industrial and institutional laundry detergents

Lubricantes / Lubricants

Muebles / Furniture

Productos textiles / Textile products

Medios de cultivo, mejoradores del suelo y mantillo / Growing media, soil improvers and mulch

Revestimientos de suelo a base de madera, corcho y bambú / Wood-, cork- and bamboo-based floor coverings

Papel gráfico / Graphic paper

Fuente: Elaboración propia.

En cuanto a la misma categoría de productos, estas son empresas que han solicitado más de 10 ecoetiquetas:

Tabla 3. Nombre de empresas españolas con ecoetiquetas y su número

\section{Total general}

Detergentes para lavavajillas a mano/

Industrias Argui, SA

Hand dishwashing detergents

Productos de limpieza de superfi-

A\&B Laboratorios de Biotecnología

cies duras / Hard surface cleaning products

Induquim, SL

Industrias Argui, SA

Laboratorios Bilper, SL

Proquimia, SA

Químicas Quimxel, SL

Soro Global, SA

Suministros científicos técnicos, SAU (SUCITESA) .. 
Pinturas y barnices para interior y exterior / Indoor and outdoor paints and varnishes

Detergentes para lavavajillas automáticos industriales e institucionales / Industrial and institutional automatic dishwasher detergents

Detergentes para ropa / Laundry detergents

Rinse-off cosmetic products

Tissue paper and tissue products
Cromology, SL 23

Industrias Quimicas Irurena, SA 28

Industrias Titán, SAU 25

Industrias Argui, SA 12

Proquimia, SA

Industrias Catalá, SA 14

Persan, SA 16

Soro Global, SA 12

Amenities Pack 12

Laboratorios Bilper, SL

Gomà-Camps Consumer, SLU ............................. 74

Industrie Cartarie Tronchetti lbérica, SLU ............... 50

Kartogroup España, SL .................................... 26

LC Paper 1881, SA ........................................... 37

Lucart Tissue \& Soap, SLU .................................... $\quad 40$

Norancell, SL .................................................... 12

Sofidel Spain, SL ………………………........... $\quad 79$

Sofidel Spain, SLU …......................................... 48

Sin embargo, analizando empresa por empresa de las 148 españolas, se ve que las ecoetiquetas solicitadas por las distintas son de pocos productos. De forma negativa sorprende que la mitad de las empresas (74 empresas) solo han certificado un único producto/servicio de su actividad (gráfico 5). El hecho de buscar un único producto demuestra el uso de la Margarita europea con un fin meramente de marketing ${ }^{23}$ aprovechando la sostenibilidad como valor de marca para el consumidor.

23 Como dice la catedrática de Ética Adela Cortina, «hemos sustituido la ética por la cosmética»; en <https:// smoda.elpais.com/placeres/adela-cortina-hemos-sustituido-la-etica-por-la-cosmetica/>. 
Gráfico 5. Número de ecoetiquetas por empresa

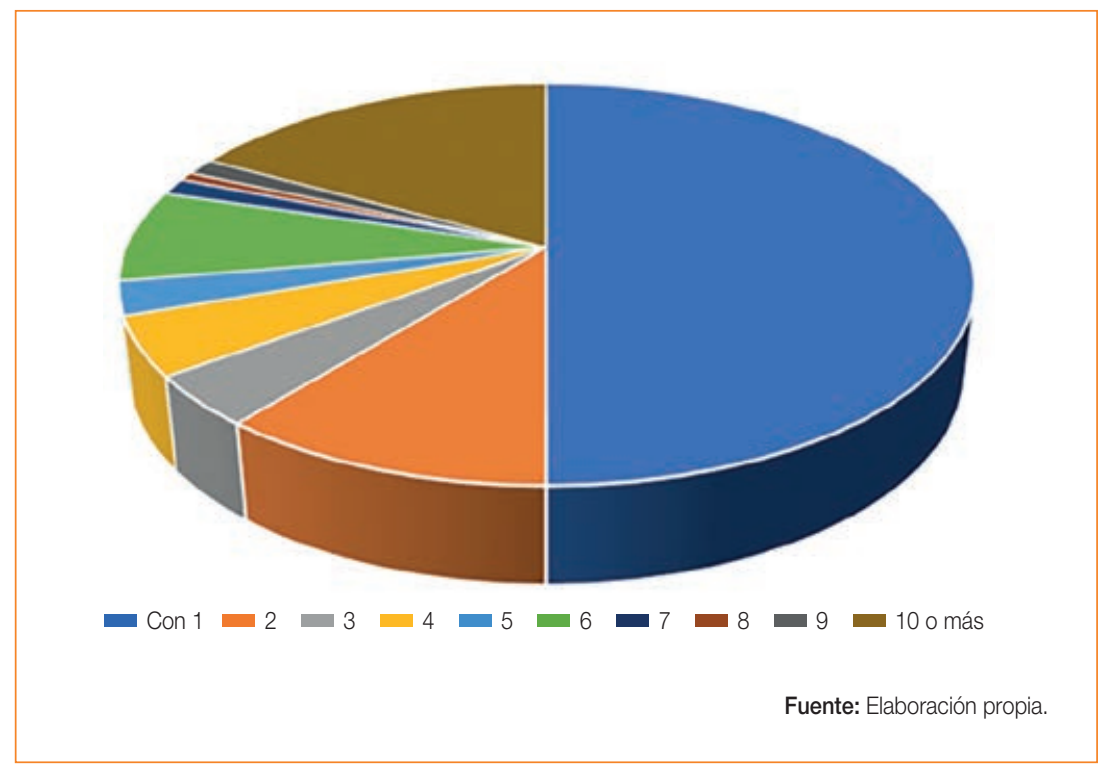

\subsubsection{Cadena de suministro}

Jabbour et al. (2015) ha señalado el efecto positivo de la gestión sostenible de la cadena de suministro y la producción baja en carbono sobre el cambio climático.

Recientemente, la cadena de suministro se ha convertido en el foco principal de la responsabilidad social empresarial. Simchi-Levi et al. (1999) definen la cadena de suministro de las corporaciones como «el proceso por el que varias organizaciones, incluidos proveedores, clientes y proveedores de logística trabajan juntos para proporcionar un paquete de productos y servicios de valor al usuario final, que es el cliente». Las empresas deben considerar no poner en peligro el medio ambiente en todas las funciones de su cadena de suministro. Evidentemente que la cadena de suministro será consecuencia de una gestión sostenible (con los instrumentos que ya hemos visto). Sin embargo, queremos resaltar como en España, en el sector juguetero, sector fuertemente descentralizado, se ha velado por la cadena de suministro, así como el canal de retorno.

En 1996, el Consejo Internacional de las Industrias del Juguete (ICTI) adoptó el código de buenas prácticas empresariales de ICTI para abordar potenciales cuestiones en las fábricas de juguetes y promover la fabricación ética en todo el mundo, particularmente en China, donde se fabrican tantos juguetes. Se estableció un plan para su puesta en práctica y en noviembre de 2003 el ICTI acreditó a los primeros auditores certificados, iniciando así el programa CARE Process. Desde la creación del Código, la ICTI y las asociaciones nacionales han trabajado para 
promocionarlo entre toda la industria. La iniciativa de ICTI ha recibido algunos reconocimientos notables desde que el código se adoptó, y la industria del juguete se ve como modelo para otras iniciativas. Algunos logros recientes incluyen el reconocimiento por la Cumbre de Líderes del Comité de Naciones Unidas Global Compact y por la Cámara de Comercio Internacional, así como la integración en el consejo rector de la Fundación ICTI Care de las principales ONG para la protección de los trabajadores, que ha ganado mucho apoyo en muy poco tiempo, con más de 320 empresas de 21 países, que representan aproximadamente el $80 \%$ del comercio mundial de juguetes, comprometidas a que a partir de una «fecha cierta» solo contratarán productos fabricados por fábricas certificadas por el ICTI. En China, el proceso ICTI Care también gana adhesiones rápidamente, con casi 2.000 fábricas ya en proceso, lo que representa casi un millón y medio de trabajadores, y más de 700 sellos de cumplimiento ya emitidos.

Estos buenos resultados han empezado a dar sus frutos también entre la distribución de juguetes. Wal-Mart, Carrefour, Toys R Us, Disney y El Corte Inglés han reconocido el código ICTI y el sello ICTI de cumplimiento, y desde que se publicó dicho acuerdo se ha multiplicado el número de solicitudes de fábricas chinas para entrar en el proceso. La iniciativa ética del ICTI es muestra de una continua actividad de la industria internacional del juguete para asegurarse de que los juguetes no son solo divertidos y seguros, sino que están fabricados en empresas que respetan la seguridad y los derechos de los trabajadores.

Por otro lado, también se ha previsto la idea del canal de retorno. Desde la Asociación Española de Fabricantes de Juguetes, el 28 de mayo de 2019, coincidiendo con el Dia Internacional del Juego, se lanzó la sexta edición. Comparte y Recicla es una acción de economía circular del sector juguetero, que alienada con los objetivos del desarrollo sostenible del planeta, aboga por el respeto del medio ambiente, la solidaridad y la integración laboral de las personas con discapacidad.

Comparte y Recicla ${ }^{24}$ funciona con una mecánica muy sencilla: los niños revisan los juguetes que se han quedado pequeños o que desean compartir con otros niños y los llevan a los puntos de recogida de juguetes, para que desde allí sean trasladados al centro de reprocesado, un centro especial de empleo, donde los juguetes son revisados uno por uno para verificar si son aptos para una segunda vida, en cuyo caso se cuentan las piezas, se limpian o se acicalan para sus nuevos dueños, y en caso de no estar en condiciones de su reutilización, se envían al reciclaje.

Los juguetes aptos para la reutilización son organizados en un banco de juguetes, que almacena los juguetes para poder atender las solicitudes de juguetes que llegan de las diferentes ONG y entidades benéficas durante todo el año a través de la web www.comparteyrecicla.com.

Estos juguetes viajan seguros gracias a la colaboración de Fundación SEUR, encargada del transporte de todos los juguetes, tanto de los puntos de recogida al centro de reprocesado, como desde ahí hasta su destino final.

${ }^{24}$ En <https://www.comparteyrecicla.com/>. 
Estas son iniciativas que favorecen la aparición de una conducta tendente a ampliar el ciclo de vida de los productos. Las aportaciones doctrinales y la propia constatación de la realidad permiten valorar, por tanto, que nos encontramos ante una nueva dimensión del marketing, aplicada a la cadena de suministro y los procesos de comercialización en torno al reciclado.

\section{Conclusiones}

Desde una perspectiva ética, hemos visto qué se puede aportar a la gestión de los Objetivos de Desarrollo Sostenible (ODS) en las empresas españolas en la sostenibilidad, desde un «pensamiento catedral», como visión de hacer algo a muy largo plazo. Desde la Unión Europea se destaca la necesidad de adoptar modelos de producción y consumo sostenibles, así como la consecución de los ODS de la Agenda 2030 de Naciones Unidas, como un planteamiento teleológico. Entre estos objetivos está el 12, que hace referencia a «Producción y consumo responsable», y más específicamente el 12.6: «Alentar a las empresas, en especial las grandes empresas y las empresas transnacionales, a que adopten prácticas sostenibles e incorporen información sobre la sostenibilidad en su ciclo de presentación de informes». Con la sostenibilidad se pretende no comprometer la capacidad de las generaciones futuras para satisfacer sus propias necesidades. Para ello, desde el marketing sostenible, las empresas enfocan parte de las actividades de la cadena de valor hacia el beneficio de la sociedad y entorno, creando valor compartido, lo que incentiva a la innovación y crecimiento económico.

Nos hemos centrado en esta investigación en la sostenibilidad medioambiental, entendida como la preservación continua de ecosistemas esenciales y sus funciones. Hemos analizado cómo determinadas empresas españolas están empezando a adoptar una actitud activa de la responsabilidad hacia la protección del medio ambiente, de conservación y reducción de impacto ambiental hacia los recursos naturales en la producción, así como productos y servicios, que proporcionan una comprensión de las direcciones locales con respecto a la agenda ambiental.

La gestión ética de los ODS ya la tiene en cuenta muchas empresas españolas en el momento de la planificación estratégica. Al implementar una gestión sostenible en la comercialización, la empresa tiene como desafíos la incorporación de estándares de sostenibilidad en las políticas de ventas, la realización de actividades que contribuyan a promover y mejorar la responsabilidad y sostenibilidad de los clientes y la verificación del grado de cumplimiento de los estándares establecidos, y todos de forma alineada. Se ha analizado la European Union's EcoManagement and Audit Scheme o EMAS, que es una herramienta de gestión voluntaria que permite evaluar, mejorar y dar a conocer el comportamiento ambiental de una empresa.

Posteriormente, se han abordado los galardones y premios europeos y el lugar de las empresas españolas, que es un indicador de éxito. En los premios EMAS, se han reconocido la labor de tres empresas españolas, tres premios de los cinco otorgados en materia 
medioambiental. En los Premios Europeos de Medio Ambiente a la Empresa (EBAE), de los seis premios, uno ha sido para una empresa española.

En último lugar, en cuanto a gestión sostenible, se ha analizado la propuesta de Forética y la norma SG21, que ha tenido una gran demanda entre los empresarios españoles en los últimos cinco años.

En el segundo bloque, en la seguridad del producto o servicio, se ha estudiado la etiqueta ecológica europea. España ocupa un lugar muy relevante en cuanto a la concesión de etiquetas, el primer lugar, pero al analizar el número de etiquetas solicitadas por empresa, se observa que más de la mitad solo ha pedido una única etiqueta. Esta falta de implicación con el resto de sus productos evidencia una instrumentalización de la etiqueta y su efecto hacia los clientes, aprovechando la sostenibilidad como valor de marca para el consumidor. Por último, se ha visto alguna iniciativa de la cadena de suministro por parte de empresas españolas, como la juguetera. En 1996, el Consejo Internacional de las Industrias del Juguete (ICTI) adoptó el código de buenas prácticas empresariales del ICTI para abordar potenciales cuestiones en las fábricas de juguetes y promover la fabricación ética en todo el mundo, particularmente en China. Por último, se ve cómo tímidamente hay alguna iniciativa sobre el canal de retorno y la posibilidad de ampliar la vida de los productos.

Consideramos que España es un país concienciado con el medio ambiente y que ve en Europa un referente donde demostrar sus decisiones. Las tendencias del mercado requieren la existencia de empresas competitivas que empleen estrategias diferenciadoras y superiores para sus clientes, para asegurar la consolidación de relaciones rentables y duraderas con ellos y el posicionamiento de sus marcas. Este estudio ha analizado ejemplos de empresas ambientalmente. El marketing verde proporciona bienes y servicios en el mercado que tienen un menor impacto ambiental, y esto se traduce en una ventaja competitiva que contribuye al éxito empresarial en un mundo altamente competitivo.

\section{Referencias bibliográficas}

Altinbasak-Farina, I. y Burnaz, S. (Eds.). (2019). Ethics, Social Responsibility and Sustainability in Marketing. Springer.

Brío, J. A. dely Junquera, B. (2004). Competitividad y Situación Medioambiental de los Centros Productivos Certificados en España. Universia Business Review, 4, 64-77.
Elkington, J. (1994). Towards the Sustainable Corporation: Win-Win-Win Business Strategies for Sustainable Development. California Management Review, 36(2), 90-100.

Fuller, D. A. (1999). Sustainable Marketing: Managerial-Ecological Issues. SAGE Publications. 
Galarraga, I. (2002). The use of eco-labels: a review of the literature. European Environment, 12(6), 316-331.

Guillén, N. (2020). La etiqueta ecológica de la Unión Europea: régimen jurídico e implementación. Actualidad Jurídica Ambiental, 98, 44-73.

Guinée, J. B. y Lindeijer, E. (Eds.). (2002). Handbook on life cycle assessment: operational guide to the ISO standards (vol. 7). Springer Science \& Business Media.

Hart y Stuart, L. (1995). A Natural-Resource-Based View of the Firm. Academy of Management Review, 20(4).

Harvanová, J. (2018). Selected aspects of integrated environmental management. Annals of Agricultural and Environmental Medicine, 25(3), 403-408.

Hawken, P. (2007). Blessed Unrest. Penguin Group.

Hunt, S. D. (2011). Sustainable marketing, equity, and economic growth: a resourceadvantage, economic freedom approach. Journal of the Academy of Marketing Science, 39(1), 7-20.

Jabbour, C. J. C., Neto, A. S., Gobbo, A. J., Ribeiro, A. y Jabbour, A. B. L. (2015). Ecoinnovations in more sustainable supply chains for a low-carbon economy: A multiple case study of human critical success factors in Brazilian leading companies. International Journal Production Economics, 164, 245-257.

Krznaric, R. (2020). The good ancestor: how to think long term in a short-term world. Random House.

Kumar, V. (2015). Evolution of marketing as a discipline: What has happened and what to look out for. Journal of Marketing, 79(1), 1-9.
Martin, D. M. y Schouten, J. (2014). Sustainable marketing. Pearson Prentice Hall.

Monfort, E. (2011). ¿Qué papel juegan las baldosas cerámicas en la compra verde y edificación sostenible? Qualicer, Foro del Recubrimiento Cerámico, 12.

Navarro, V. G. y Revilla, G. G. (2020). La incorporación de los objetivos de desarrollo sostenible como factor de competitividad empresarial. Información Comercial Española, ICE: Revista de economía, 912, 75-86.

Rivera, J. (2007). Re-evaluating Green Marketing Strategy: a Stakeholder Perspective. European Journal of Marketing, 451(11/12), 1.328-1.358.

Rodríguez, M. (29 de diciembre de 2020). Qué es el "pensamiento catedral», una de las grandes lecciones de 2020 según el filósofo Roman Krznaric. BBC News Mundo. https://www.bbc.com/mundo/ noticias-55448362

Simchi-Levi, D., Simchi-Levi, E. y Kaminsky, P. (1999). Designing and managing the supply chain: Concepts, strategies, and cases. McGraw-Hill.

Valle, S. S. del (2010). Gestión estratégica: clave para la responsabilidad social de las empresas. Dimensión Empresarial, 8(2), 24-37.

Van Dam, Y. K. y Apeldoorn, P. A. (1996). Sustainable marketing. Journal of Macromarketing, 16(2), 45-56.

WCED, S. W. S. (1987). World commission on environment and development. Our common future, 17(1), 1-91.

Yilmazer, M. y Onay, M. (2019). Dynamics of Sustainable Entrepreneurship: A Proposed 4S Model. En Ethics, Social Responsibility and Sustainability in Marketing (pp. 237261). Springer. 